\title{
SECAGEM DE PASTA DE VEGETAIS ENRIQUECIDA DE SANGUE BOVINO: AVALIAÇÃO DAS PROPRIEDADES FUNCIONAIS E NUTRICIONÄIS DAS PROTEÍNAS
}

\author{
M. L. MONTE ${ }^{1}$, S. F. da ROCHA ${ }^{1}$, M. C. K. RODRIGUES ${ }^{1}$, A. P. Q. LARROSA ${ }^{1}$, L. A. A. \\ PINTO $^{1}$ \\ ${ }^{1}$ Universidade Federal de Rio Grande, Escola de Química e Alimentos \\ E-mail para contato: michelimonte@gmail.com
}

\begin{abstract}
RESUMO - O setor agrícola é responsável por gerar perdas pós-colheita, e a operação de secagem é muito utilizada para reduzir estas perdas e aumentar a conservação destes alimentos. O sangue bovino possui alto valor nutricional, devido às proteínas de alta digestibilidade, podendo ser adicionado em diversos produtos, evitando a contaminação ambiental. Assim, o objetivo desse estudo foi avaliar as propriedades funcionais e nutricionais de uma pasta de vegetais enriquecida com sangue bovino, obtida com a técnica de programação linear maximizando o teor de proteínas, seca em leito de jorro. Foi utilizado um secador de geometria cone-cilíndrica com as seguintes condições: vazão de alimentação $(400$ e $600 \mathrm{~mL} / \mathrm{h})$ e temperatura do ar $\left(90^{\circ} \mathrm{C}\right.$ e $\left.110^{\circ} \mathrm{C}\right)$. Foram analisadas: solubilidade proteica, índice de retenção de água, índice de solubilidade em água e digestibilidade proteica. A maior vazão de alimentação $(600 \mathrm{~mL} / \mathrm{h})$ e maior temperatura $\left(110^{\circ} \mathrm{C}\right)$ proporcionaram o aumento da solubilidade proteica (superior a $80 \%$ ), apresentando características tecnológica para utilização desta pasta em outros produtos.
\end{abstract}

\section{INTRODUÇÃO}

No setor agrícola são registrados altos índices de perdas pós- colheita e perecibilidade gerando o desperdício de alimentos. Neste contexto, a secagem de alimentos de origem vegetal vem sendo utilizada como uma prática importante para reduzir o teor de umidade e aumentar o tempo de conservação dos mesmos, e com isso melhorando o aproveitamento da produção agrícola (Massaro e Pinto, 2002; Oliveira e Freitas, 2004).

O sangue proveniente do abate de animais é caracterizado pelo elevado valor nutricional, em virtude de suas proteínas, ricas em aminoácidos essenciais e de alta digestibilidade, suas vitaminas e seus sais minerais (Pardi et al., 1994). Este subproduto que é destinado para a fabricação de rações e fertilizantes, ou muitas vezes, lançado em mananciais hídricos, poderia ter um aproveitamento mais intensivo e racional para a alimentação humana (Pacheco, 2006; Moure et al., 1998).

A elaboração de pasta de vegetais enriquecida com sangue bovino apresenta-se como uma alternativa para o aproveitamento destes excedentes agropecuários. A secagem em leito de jorro apresenta como vantagem o reduzido tempo de residência do produto no equipamento, obtendo uma melhor conservação das suas características sensoriais, nutricionais e tecnológicas (Shuhama et al., 2003). As propriedades funcionais e nutricionais das proteínas podem ser afetadas pela temperatura do ar de secagem, e o aquecimento excessivo pode provocar desnaturação seguida de degradação, o que implica na baixa 
disponibilidade de grupos polares para fixar água (Demetriades e Mc Clements, 2000).

Diante disso, o objetivo desse estudo foi avaliar as propriedades funcionais e nutricionais das proteínas de uma pasta de vegetais enriquecida com sangue bovino seca em leito de jorro, utilizando a programação linear para a maximização do teor de proteínas da pasta.

\section{MATERIAL E MÉTODOS}

\subsection{Formulação da Pasta}

A pasta foi constituída dos seguintes vegetais: cebola branca (Allium cepa L.), tomate longa vida (Lycopersicum esculentum), cenoura (Daucuscarota L.), couve (Brassica oleracea), batata (Solanum tuberosum), sendo também adicionados óleo de soja comercial e sangue bovino. Os vegetais e o óleo de soja foram adquiridos em feiras livres/mercados da cidade do Rio Grande/RS. O sangue bovino foi coletado em sistema aberto em um abatedouro de pequeno porte, situado na cidade de Pelotas-RS, com as práticas de assepsia devidamente empregadas (Massaro e Pinto, 2002).

A quantidade de cada constituinte foi determinada através da programação linear com o uso do aplicativo Microsoft Solver Excel que permite obter a maximização do conteúdo proteico, utilizando restrições de teor de carboidratos, proteínas, lipídios e valor calórico (Larrosa, 2012). As restrições utilizadas para formular a pasta de vegetais enriquecida com sangue bovino foram de $50-70 \%(\mathrm{~m} / \mathrm{m})$ para carboidratos, $10-20 \%(\mathrm{~m} / \mathrm{m})$ para proteínas, $4 \%$ $(\mathrm{m} / \mathrm{m})$ para lipídios e 200-500 kcal para valor calórico.

A função objetiva (maximização do teor proteico) é uma equação linear que relaciona os constituintes com seus respectivos teores proteico, segundo a Equação 1.

$$
P_{T}=\sum_{i=1}^{n} m_{i \cdot} \cdot P_{i}
$$

As funções de restrição Equações 2-12 são equações e inequações que limitam a função a ser otimizada. A Equação 2 relaciona as massas dos constituintes em base seca.

$$
C_{B S}=m 1+m 2+m 3+m 4+m 5+m 6+m 7
$$

As Inequações 3 e 4 limitam o conteúdo de carboidratos $(C)$; as Inequações 5 e 6 limitam o conteúdo de proteínas $(P)$; as Inequações 7 e 8 limitam o conteúdo de lipídios $(L)$; as Inequações 9 e 10 limitam o valor calórico $(V c)$; as Inequações 11 e 12 restringem a possibilidade de valores negativos para quantidade de massa e dos constituintes com quantidade máxima estabelecida, respectivamente.

$$
\begin{aligned}
& \sum_{i=1}^{i=7} m_{i} \cdot c_{i} \geq C_{1} \\
& \sum_{i=1}^{i=7} m_{i} \cdot c_{i} \leq C_{2}
\end{aligned}
$$




$$
\begin{aligned}
& \sum_{i=1}^{i=7} m_{i} \cdot p_{i} \geq P_{1} \\
& \sum_{i=1}^{i=7} m_{i} \cdot p_{i} \leq P_{2} \\
& \sum_{i=1}^{i=7} m_{i} \cdot l_{i} \geq L_{1} \\
& \sum_{i=1}^{i=7} m_{i} \cdot l_{i} \leq L_{2} \\
& \sum_{i=1}^{i=7} m_{i} \cdot v c_{i} \geq V C_{1} \\
& \sum_{i=1}^{i=7} m_{i} \cdot v c_{i} \leq V C_{2} \\
& m_{i} \geq 0 \\
& m_{i} \leq m
\end{aligned}
$$

Após a quantificação otimizada dos constituintes pela programação linear considerando o teor de proteína, foi realizada a obtenção da pasta de vegetais segundo as etapas descritas na Figura 1.

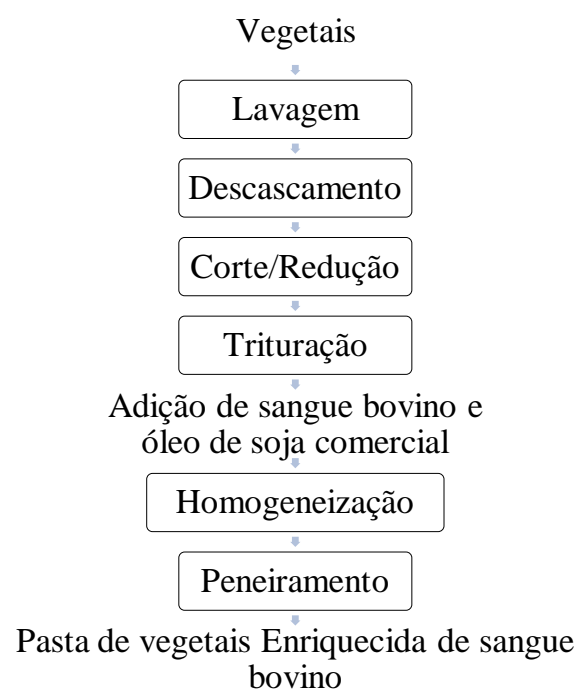

Figura 1 - Fluxograma do processo de obtenção da pasta de vegetais enriquecida de sangue bovino.

\subsection{Secagem em Leito de Jorro}


A secagem foi realizada em célula de leito de jorro cone-cilíndrica composto por uma coluna cilíndrica com diâmetro de $17,5 \mathrm{~cm}$ e altura de $75 \mathrm{~cm}$, bases inferior e superior com cones de vidro com ângulo de $60^{\circ}$ e altura de $15 \mathrm{~cm}$ cada. O diâmetro de entrada $(\mathrm{Di})$ da célula foi de $2,9 \mathrm{~cm}$ sendo a relação $(D c / D i)$ igual a 6,0 . Na parte superior da coluna havia uma saída para o ar com diâmetro de $25 \mathrm{~mm}$, a qual foi conectada com um ciclone do tipo Lapple, com diâmetro de $100 \mathrm{~mm}$. A pasta desidratada foi coletada em um recipiente de vidro acoplada na saída do ciclone. O leito de inertes foi constituído por 2,0 kg de partículas de polietileno com diâmetro médio de $3,2 \mathrm{~mm}$, esfericidade 0,7 e densidade de $0,96 \mathrm{~g} / \mathrm{cm}^{3}$. A pasta apresentava uma concentração de $10 \%(\mathrm{~m} / \mathrm{m})$ de sólidos, e foi alimentada no leito com sistema contínuo através de uma bomba peristáltica.

O fluido utilizado na secagem foi ar aquecido por um sistema de três resistores de 800 Watts cada um. As determinações de vazão de ar foram feitas por meio de placa de orifício acoplada a um manômetro de tubo inclinado. As medidas de temperaturas para acompanhar os experimentos de secagem foram feitas por termopares cobre-constantan. Foram fixadas a pressão de atomização da alimentação em $200 \mathrm{kPa}$ absoluta e a taxa de circulação de $100 \%$ acima da velocidade de jorro mínimo.

\subsection{Análise Estatística}

Foram estudadas duas varáveis de estudo na secagem de pasta de vegetais como, vazão de alimentação da pasta (400 e $600 \mathrm{~mL} / \mathrm{h})$ e temperatura de entrada do ar $(90$ e $110^{\circ} \mathrm{C}$ ). Os resultados foram analisados através do Teste de Tukey ao nível de $95 \%$ de confiança $(\mathrm{p}<0,05)$.

\subsection{Metodologia Analítica}

Determinação da solubilidade proteica: A determinação da solubilidade proteica em meio aquoso da pasta desidratada foi feita pelo método Morr et al. (1985). Adicionou-se aproximadamente $2,5 \mathrm{~g}$ de amostra em $50 \mathrm{~mL}$ de água destilada, a seguir levou-se ao agitador magnético por 15 min e posterior centrifugação a $3500 \times$ g por 15 min. Após, filtrou-se o conteúdo dos tubos, e procedeu-se a determinação de proteína do sobrenadante. O índice de proteína solúvel $(P S)$ foi determinado sobre o conteúdo total de proteína das amostras e o teor de proteína solúvel como mostra a Equação 13.

$$
P S=\frac{A \times 50}{W \times \frac{S}{100}} \times 100
$$

Determinação da Capacidade de retenção de água $(C R A)$ e Índice de Solubilidade em água (ISA): A capacidade de retenção de água e índice de solubilidade em água foram quantificados segundo adaptações de Anderson et al. (1969). Elaborou-se uma mistura contendo 2,5 g de amostra e $30 \mathrm{~mL}$ de água, depois de mantida sob agitação por $30 \mathrm{~min}$ e posteriormente centrifugada a $5000 \times \mathrm{g}$ por $15 \mathrm{~min}$, na temperatura de $24{ }^{\circ} \mathrm{C}$. O sedimento foi então pesado e, no sobrenadante, determinado resíduo seco (sólido solúveis) após evaporação. Os índices foram então calculados de acordo com as Equações 14 e 15.

$$
\text { C.R.A. }=\frac{M_{r c}}{\left(M_{a}-M_{r e}\right)}
$$




$$
\text { I.S.A. }=\frac{M_{r e} \cdot 100}{M_{a}}
$$

Digestibilidade proteica in vitro: A digestibilidade foi realizada utilizando as enzimas pepsina e pancreatina, simulando as condições características do trato gastrointestinal, segundo Sgarbieri (1996). Em erlenmeyer, 1,00 g de amostra foi hidrolisado com solução de pepsina $1,5 \mathrm{mg} / \mathrm{mL}$ em $\mathrm{HCl} 0,1 \mathrm{~N}$ na proporção 1:10 (enzima:proteína) durante $3 \mathrm{~h}$ à $37{ }^{\circ} \mathrm{C}$ e $150 \mathrm{rpm}$. Ao final o pH das amostras foi elevado a 7,0, utilizando solução de $\mathrm{NaOH} 0,3 \mathrm{~N}$ e foi adicionada solução de pancreatina $1,5 \mathrm{mg} / \mathrm{mL}$ em tampão fosfato $\mathrm{pH} 8,0$ na proporção 1:10 (enzima:proteína). As amostras foram mantidas sob agitação $(130 \mathrm{rpm})$ à $37^{\circ} \mathrm{C}$ por $24 \mathrm{~h}$. Após a hidrólise, foi adicionado TCA $40 \%(\mathrm{~m} / \mathrm{m})$ para precipitação do material não digerido, ficando as amostras em repouso por $1 \mathrm{~h}$ no refrigerador. Após, as amostras foram centrifugadas a $3220 \mathrm{rpm}$ durante 15 min e filtradas com papel filtro. No sobrenadante foi determinado o teor de aminoácidos liberados, pelo método de Lowry et al. (1951), empregando uma curva padrão de tirosina cuja concentração variou entre 0,01 a $0,1 \mathrm{mg} / \mathrm{mL}$.

\section{RESULTADOS E DISCUSSÃO}

A Tabela 1 apresenta a formulação otimizada pela programação linear, que foi utilizada para produção de $100 \mathrm{~g}$ de pasta de vegetais enriquecida com sangue bovino.

Tabela 1 - Quantidades dos constituintes otimizadas para formulação da pasta de vegetais enriquecida com sangue bovino.

\begin{tabular}{cc}
\hline Constituintes & Quantidade $(\mathrm{g})$ \\
\hline Cebola branca & 265,9 \\
Tomate & 205,9 \\
Cenoura & 237,5 \\
Couve & 115,8 \\
Batata & 37,5 \\
Óleo de soja & 2,1 \\
Sangue bovino & 35,3 \\
\hline
\end{tabular}

Observa-se na Tabela 1 que a cebola, tomate e a cenoura apresentaram maiores quantidades na formulação em relação aos demais constituintes. Isso se deve ao fato de que na programação linear os valores de carboidratos foram fixados entre 50 e $70 \%$ $(\mathrm{m} / \mathrm{m})$, e como estes vegetais apresentam em sua composição química as maiores proporções de carboidratos, representaram as maiores quantidades. Apesar de que foi utilizado como função objetiva de maximizar o teor proteico, não necessariamente os constituintes que possuem maior quantidade de proteínas seriam otimizadas em quantidades maiores. A Tabela 2 apresenta os resultados quanto à solubilidade proteica, capacidade de retenção de água (CRA), índice de solubilidade em água (ISA) e digestibilidade proteica dos produtos desidratados no secador de leito de jorro e in natura. 
Tabela 2 - Solubilidade proteica, CRA, ISA e digestibilidade proteica in vitro dos produtos desidratados e in natura.

\begin{tabular}{|c|c|c|c|c|}
\hline $\begin{array}{l}\text { Tratamentos } \\
\qquad\left(\mathrm{n}^{\mathrm{o}}\right)\end{array}$ & $\begin{array}{c}\text { Solubilidade } \\
\text { Proteica (\% } \\
\text { m/m)* }\end{array}$ & $C R A(\mathrm{~g} / \mathrm{g})^{*}$ & $I S A(\% \mathrm{~m} / \mathrm{m})^{*}$ & $\begin{array}{l}\text { Digestibilidade } \\
\text { proteica in } \\
\text { vitro }(\% \mathrm{~m} / \mathrm{m})\end{array}$ \\
\hline $\begin{array}{c}(1) \\
400 \mathrm{~mL} / \mathrm{h} 90^{\circ} \mathrm{C} \\
(2)\end{array}$ & $66,2 \pm 0,6^{\mathrm{a}}$ & $4,6 \pm 0,1^{\mathrm{a}}$ & $32,8 \pm 1,3^{\mathrm{a}}$ & $69,4 \pm 0,6^{\mathrm{a}}$ \\
\hline $\begin{array}{c}400 \mathrm{~mL} / \mathrm{h} \\
110^{\circ} \mathrm{C}\end{array}$ & $63,5 \pm 0,4^{b}$ & $4,1 \pm 0,1^{b}$ & $33,1 \pm 0,8^{\mathrm{a}}$ & $77,3 \pm 0,6^{b}$ \\
\hline $\begin{array}{c}(3) \\
600 \mathrm{~mL} / \mathrm{h} 90^{\circ} \mathrm{C} \\
(4)\end{array}$ & $57,3 \pm 2,2^{\mathrm{c}}$ & $4,3 \pm 0,1^{\mathrm{b}}$ & $40,8 \pm 0,8^{b}$ & $67,7 \pm 0,4^{\mathrm{c}}$ \\
\hline $\begin{array}{c}600 \mathrm{~mL} / \mathrm{h} \\
110^{\circ} \mathrm{C}\end{array}$ & $84,7 \pm 2,3^{\mathrm{d}}$ & $3,8 \pm 0,1^{\mathrm{c}}$ & $34,8 \pm 1,4^{\mathrm{a}}$ & $78,5 \pm 0,8^{\mathrm{d}}$ \\
\hline In natura & $36,1 \pm 0,7^{\mathrm{e}}$ & --- & --- & $76,7 \pm 0,5^{\mathrm{c}}$ \\
\hline
\end{tabular}

*Valor médio \pm erro médio (em triplicata). $(\% \mathrm{~m} / \mathrm{m})$ : percentagem em massa. Letras diferentes na mesma coluna apresentam diferença significativa $(\mathrm{p}<0,05)$.

Em relação aos resultados da solubilidade proteica mostrados na Tabela 2, todos os experimentos apresentaram diferença significativa $(\mathrm{p}<0,05)$, sendo que o maior valor foi para o experimento $600 \mathrm{~mL} / \mathrm{h}$ e $110^{\circ} \mathrm{C}$. Observou-se que a secagem proporcionou um aumento da solubilidade proteica quando comparada a pasta in natura. A temperatura de secagem de $110^{\circ} \mathrm{C}$, fez com que as proteínas sofressem uma modificação estrutural deixando os grupos proteicos susceptíveis a solubilização em água. Como a secagem em leito de jorro é um processo de desidratação contínuo, o produto alcança temperaturas em torno de $5^{\circ} \mathrm{C}$ acima da temperatura de bulbo úmido do ar de entrada, que nesses experimentos ficou entre $35^{\circ} \mathrm{C}$ e $37^{\circ} \mathrm{C}$.

Na Tabela 2 observa-se que a capacidade de retenção de água ficou com valores entre 3,8 a 4,6 g/g, sendo que os experimentos de $90^{\circ} \mathrm{C}$ resultaram em maiores valores de $C R A$. Em relação ao índice de solubilidade em água apenas o experimento $(600 \mathrm{~mL} / \mathrm{h}$ a $\left.90^{\circ} \mathrm{C}\right)$ apresentou diferença significativa $(\mathrm{p}<0,05)$ em relação aos demais, apresentando o maior valor.

Larrosa et al (2011) encontraram para uma pasta de vegetais seca em leito de jorro, uma solubilidade proteica em meio aquoso de $29,1 \%(\mathrm{~m} / \mathrm{m})$, capacidade de retenção de água de 4,2 g/g e índice de solubilidade em água de 14,9\% (m/m). Pode-se observar, que ao adicionar o sangue obteve-se valores superiores para as propriedades funcionais das proteínas. As proteínas globulinas e albuminas do sangue bovino são altamente solúveis e bastante hidrofílicas, o que lhes confere boas características geleificantes e de retenção de água (Xiong, 2009).

A Tabela 2 também apresenta os resultados para a digestibilidade proteica in vitro, que mostraram diferenças significativas ao nível de $95 \%(\mathrm{p}<0,05)$ entre os tratamentos e a pasta in natura. O experimento de $600 \mathrm{~mL} / \mathrm{h}$ e $110^{\circ} \mathrm{C}$ proporcionou o maior aumento da digestibilidade proteica em relação à pasta in natura. Segundo Araújo (1995), a desnaturação parcial das proteínas melhora a digestibilidade e a disponibilidade biológica de aminoácidos essenciais. 
Através das avaliações, pode-se considerar que a melhor condição de secagem foi o tratamento de $600 \mathrm{~mL} / \mathrm{h}$ e $110^{\circ} \mathrm{C}$. Isto pode ser explicado, pois ao alimentar uma maior quantidade de sólidos no leito, com uma maior temperatura, ocorre um aumento da espessura da camada que envolve os inertes e consequentemente a temperatura de saída é menor, ocorrendo uma menor degradação pela ação do calor.

\section{CONCLUSÃO}

Pode-se considerar a melhor condição de secagem o tratamento de $600 \mathrm{~mL} / \mathrm{h}$ e $110^{\circ} \mathrm{C}$ em que obteve-se um aumento de $80 \%$ na solubilidade proteica em relação àpasta in natura e uma digestibilidade proteica de $78,5 \%(\mathrm{~m} / \mathrm{m})$. Os resultados da capacidade de retenção de água $(C R A)$ e índice de solubilidade em água (ISA) apresentaram valores maiores para os tratamentos de $90^{\circ} \mathrm{C}$, mesmo assim todos os tratamentos apresentaram-se dentro de uma faixa de 3,8 a 4,6 g/g para o $C R A$ e 33,0 a $41,0 \%(\mathrm{~m} / \mathrm{m})$ para o $I S A$. Através das avaliações funcionais e nutricionais pode-se concluir que a pasta de vegetais enriquecida de sangue bovino seca em leito de jorro apresentou boas características tecnológicas para a utilização em outros produtos.

\section{NOMENCLATURA}

$A$ - concentração proteica em $(\mathrm{mg} / \mathrm{mL})$

$C_{1}$ - valor mínimo de carboidratos $(\% \mathrm{~m} / \mathrm{m})$

$C_{2}$ - valor máximo de carboidratos $(\% \mathrm{~m} / \mathrm{m})$

$\mathrm{C}_{\mathrm{BS}}$ - somatório dos constituintes da pasta em base seca

$c_{i}$ - quantidade de carboidratos de cada constituinte $(\mathrm{g} / 100 \mathrm{~g})$

$L_{l}$-valor mínimo de lipídios $(\% \mathrm{~m} / \mathrm{m})$

$L_{2}$ - valor máximo de lipídios $(\% \mathrm{~m} / \mathrm{m})$

$l_{i}$ - quantidade de lipídios de cada constituinte em (g/100g)

$m$ - quantidade máxima de cada constituinte (g)

$M a$ - massa de amostra utilizada $(\mathrm{g})$

Mrc - massa de precipitado $(\mathrm{g})$

Mre - massa de resíduo evaporado $(\mathrm{g})$

$P_{1}$ - valor mínimo de proteínas $(\% \mathrm{~m} / \mathrm{m})$

$P_{2}$ - valor máximo de proteínas $(\% \mathrm{~m} / \mathrm{m})$

$p_{i}$ - quantidade de proteínas de cada constituinte $(\mathrm{g} / 100 \mathrm{~g})$

$p_{i}$ - quantidade de proteínas de cada constituinte $(\mathrm{g} / 100 \mathrm{~g})$

$P S$ - proteína solúvel

$P T$ - Proteína total $(\% \mathrm{~m} / \mathrm{m})$

$S$ - concentração de proteína na amostra

$V c_{1}$ - valor mínimo de valor calórico (kcal)

$V c_{2}$ - valor máximo de valor calórico (kcal)

$v c i$ - valor calórico de cada constituinte $(\mathrm{kcal} / 100 \mathrm{~g})$

$W$ - massa de amostra (mg)

\section{REFERÊNCIAS}

ANDERSON, R.A.; CONWAY, H.F.; PFEIFER, U.F.; GRIFFIN JR., E.L. Gelatination of corn grits by roll and extrusion cooking.Cereal Sci. Today, v. 14, n. 1, p. 4-7, 1969. 
ARAÚJO, J. M. A. Química de Alimentos: teoria e prática. $1^{\text {a }}$ ed. Viçosa: Universidade Federal de Viçosa, 1995.

DEMETRIADES, K., McCLEMENTS, J. D. Influence of sodium dodecyl sulfate on the physicochemical properties of whey protein-stabilized emulsions. Colloids Surfaces, v. 161, p. 391-400, 2000.

LARROSA, A. P. Q. Secagem de pasta de vegetais: análise da operação em leito de jorro e caracterização do produto final. Rio Grande: FURG, 2012. 129 p. Dissertação. (Mestrado em Engenharia e Ciência de Alimentos).

LARROSA, A. P. Q.; MUSZINSKI, P.; PINTO, L. A. A.; Programação linear para formulação de pasta de vegetais e operação de secagem em leito de jorro. Ciência Rural, v. 41, n.11, p. 2032-2038, 2011.

LOWRY, O. H.; ROSENBROUGH, M. J.; FARR, A. L.; RANDALL, R. J. Protein measurement with the Folin Phenol Reagent. J. Biol. Chem., v.193, pp. 265-275, 1951.

MASSARO, A.; PINTO, L. A. A. Enriquecimento proteico de farelo de arroz desengordurado com sangue bovino, utilizando a técnica de leito de jorro. Revista Instituto Adolfo Lutz, v. 61, n. 2, p. 77-84, 2002.

MORR, C. V.; GERMAN, B.; KINSELA, J. E.; REGENSTEIN, J. M.; VAN-BUREN, J. P.; KILARA, A.; LEWIS, B. A.; MAGNINO, M. E. Collaborative study to develop a standardized food protein solubility procedure. J. Food Sci., v. 50, p.1715-1718, 1985.

MOURE, F.; RENDUELES, M.; DÍAZ, M. Aproveitamento del plasma procedente de sangre de mataderos. Alimentaria, n. 290, p. 41-50, 1998.

OLIVEIRA, H. V.A., FREITAS, L.A.P. The effect of processing factors on the efficiency of hard gelatin capsules coating in a spouted bed. In: INTERNATIONAL DRYING SYMPOSIUM, 14., 2004, São Paulo. Proceedings of the 14th International Drying Symposium. São Paulo:v. B, p. 852-859.

PACHECO, J. W. Guia técnico ambiental de abates (bovino e suíno). São Paulo: CETESB, 2006.

PARDI, M. C.; SANTOS, I. F.; SOUZA, E. R.; PARDI, H. S.Ciências, higiene e tecnologia da carne. Goiânia: Universidade Federal de Goias, v. 2, p. 1110, 1994.

SGARBIERI, V. C. Proteínas em alimentos proteicos. São Paulo: Varela, 1996.

SHUHAMA, I. K.; AGUIAR, M. L.; OLIVEIRA, W. P.; FREITAS, L. A. P. (2003). Experimental production of annatto powders in spouted bed dryer. J. Food Eng., 59, p.93-97.

XIONG, Y.L. Dairy proteins. In. Tarté, R. Ingredients in meat products: properties, functionality and applications. New York: Springer.p. 131-143, 2009. 